\title{
LEISHMANIASIS IN CENTRAL AND SOUTHERN TUNISIA: CURRENT GEOGRAPHICAL DISTRIBUTION OF ZYMODEMES
}

\author{
HAOUAS N.*, GORCII M.*, CHARGUI N.*, AOUN K.**, BOURATBINE A.**, MESSAADI AKROUT F.***, \\ MASMOUDI A.*****, ZILI J.******, BEN SAID M.*******, PRATLONG F.********, DEDET J.P.*********, MEZHOUD H.*, \\ AZAIEZ R.* \& BABBA H.*
}

\section{Summary:}

The authors report the identification of Leishmania strains isolated from the Centre and the South of Tunisia. 266 strains were isolated between 1998 and 2006 from human ( $n=221$ strains) and dogs ( $n=45$ strains) hosts. The isoenzymatic identification exhibits the presence of in total five zymodemes belonging to three Leishmania complexes: Leishmania infantum, L. major and L. killicki. All strains isolated from human and canine visceral leishmaniasis belonged to L. infantum. zymodeme MON-1 was the only one isolated from canine visceral leishmaniasis. However, it is predominant in human visceral leishmaniasis beside zymodeme MON-24 which was detected in two provinces of the Centre (Monastir and Kairouan) and zymodeme MON-80 isolated for the first time in Kairouan province. Three complexes are responsible for human cutaneous leishmaniasis: L. major MON-25 is the parasite the most frequently found in its classic foci in the Centre and the South of the country. L. infantum MON-24 was isolated for the first time in a small locality of Sfax (southern Tunisia) showing the appearance of a new focus of $L$. infantum. L. killicki was isolated in its original focus of Tataouine and in two new foci of the central part of the country (Sidi Bouzid and Kairouan)

KEY WORDS : cutaneous leishmaniasis, visceral leishmaniasis, Leishmania major, Leishmania infantum, Leishmania killicki, Tunisia.
Résumé : Les leISHMANIOSES AU CENTRE ET AU SUD DE LA TUNISIE DISTRIBUTION GÉOGRAPHIQUE ACTUELLE DES ZYMODÈMES

Les auteurs rapportent l'identification de souches de Leishmania isolées au centre et au sud de la Tunisie. 266 souches ont été isolées entre 1998 et 2006 à partir de l'homme ( $n=221$ souches) et du chien ( $n=45$ souches). L'identification isoenzymatique de ces isolats à permis de mettre en évidence la présence de cinq zymodèmes appartenant à trois complexes leishmaniens Leishmania infantum, L. major et L. killicki. Tous les isolats provenant de patients atteints de leishmaniose viscérale ainsi que des chiens leishmaniens appartiennent au complexe L. infantum.

Seul le zymodème MON-1 est isolé de chiens ayant la leishmaniose viscérale. Cependant, il est prédominant dans le cas de la leishmaniose viscérale humaine à côté du zymodème MON24 qui a été isolé dans deux gouvernorats du centre Monastir et Kairouan) et du zymodème MON-80 isolé pour la première fois dans la région de Kairouan. Trois complexes sont responsables de la leishmaniose cutanée humaine : le complexe L. major zymodème MON-25 est le parasite le plus fréquemment trouvé dans les foyers classiques de la leishmaniose cutanée zoonotique du centre et du sud tunisien. Le complexe L. infantum MON-24 est isolé pour la première fois dans une petite délégation du gouvernorat de Stax au sud tunisien montrant ainsi l'apparition d'un nouveau foyer de L. infantum. Le complexe L. killicki responsable de la leishmaniose cutanée anthroponotique est isolé dans son foyer original à Tataouine ainsi que dans deux nouveaux foyers au centre du pays (Sidi Bouzid et Kairouan) signalant le début d'extension de ce complexe.

MOTS CLÉS : leishmaniose cutanée, leishmaniose viscérale, Leishmania major, Leishmania infantum, Leishmania killicki, Tunisie.

\section{INTRODUCTION}

T n Tunisia, three complexes of the Leishmania (L.) genus are responsible for visceral and cutaneous leishmaniasis disease. Each complex is located in a

\footnotetext{
* Laboratoire de Parasitologie-Mycologie (99UR/08-05), Faculté de Pharmacie, Département de Biologie, Clinique B, 1 Rue Avicenne, 5000 Monastir, Tunisia.

** Laboratoire de Parasitologie-Mycologie, Institut Pasteur de Tunis, **** Laboratoire de Parasitologie, Centre d'Hygiène de Sfax, ***** Service Dermatologie, EPS Hedi Chaker, Sfax, ****** Service Dermatologie, EPS Fattouma Bourguiba,Monastir, ******* Laboratoire de Parasitologie-Mycologie, EPS Farhat Hached, Sousse, Tunisia.

********* Laboratoire de Parasitologie, Centre National de Référence des Leishmania, CHU, 34090 Montpellier, France.

Correspondence: Hamouda Babba.

Tel.: 0021673448666 - Fax: 0021673461830

E-mail: hamouda.babba@gnet.tn
}

focus of the country: $i$ ) Sporadic cutaneous leishmaniasis (SCL) and Visceral leishmaniasis (VL) due to L. infantum occur in the North and the Centre of Tunisia (Bel Hadj et al., 2000; Bel Hadj et al., 2002a); ii) Zoonotic cutaneous leishmaniasis (ZCL) due to L. major complex is distributed in the Centre and the South of the country (Zahaf et al., 1986); iii) However, Chronic cutaneous leishmaniasis (CCL) caused by L. killicki complex has a limited geographical area in the micro focus of Tataouine in southeast Tunisia (Rioux et al., 1986b). Human CL and human VL have been known since 1884 and 1904 respectively (Deperet \& Bobinet, 1884; Laveran \& Cathoire, 1904). But a precise characterization of the parasite circulating in these foci started only in 1981 (Lanotte et al., 1981). Since then, L. infantum foci of the North of Tunisia have been intensively stu- 
died by various authors at Institut Pasteur of Tunisia and the Parasitological laboratory "Etablissement Publique de Santé" (EPS) La Rabta Tunis (Aoun et al., 2000; Bel Hadj et al., 2002b). However, ZCL and CCL foci of the Centre and the South have been rarely studied and no recent data have been published concerning these foci. Indeed, the latest study carried on $\mathrm{CL}$ in Tunisia, has included 71 strains which is the biggest number of identified CL strain until now, but only 12 studied strains originated from the Centre and the South of Tunisia (Kallel et al., 2005). This little number of strains does not represent the epidemiological feature of leishmaniasis in these central and southern foci. The present report aims to complete the epidemiological studies of leishmaniasis in the remaining parts of the country and to update the result of characterization of these strains. The systematic identification of Leishmania strains should make possible to understand the epidemiological feature of the parasite in these endemic foci.

\section{MATERIALS AND METHODS}

\section{STRAINS STUDIED}

66 strains were isolated between 1998 and 2006 in different endemic regions of the Centre (Monastir, Mahdia, Kairouan and Sidi Bouzid) and the
South of the country (Sfax, Gafsa, Tataouine, Kasserine and Tozeur) (Table I). The strains were obtained from 37 cases of human visceral leishmaniasis, 184 cases of human cutaneous leishmaniasis and 45 cases of canine visceral leishmaniasis. 21 of the human VL isolates were from bone marrow and 16 from peripheral blood.

All strains obtained from human CL were isolated from skin. However, strains obtained from canine VL were isolated from popliteal lymphe nodes ( $\mathrm{n}=11$ isolates), from blood ( $\mathrm{n}=9$ isolates), from bone marrow $(\mathrm{n}=$ 9 isolates), from spleen ( $\mathrm{n}=9$ isolates) and from liver ( $n=7$ isolates).

The collection of human strains ( $n=221$ isolates) has been made within the context of diagnostic investigation in laboratories hospitals in Tunisia. In fact, 67 strains came from EPS Fattouma Bourguiba Monastir, 86 from Centre d'Hygiène de Sfax, 53 from Laboratoire de Parasitologie Institut Pasteur de Tunis and 15 from EPS Farhat Hached de Sousse. However, canine strains ( $n=45$ isolates) were obtained from field epidemiological studies (18 isolates) and from veterinary diagnostic services (27 isolates).

\section{REFERENCE STRAINS}

The four reference strains of Leishmania used in this study were provided by the Centre National de Réfé-

\begin{tabular}{|c|c|c|c|c|}
\hline \multirow[b]{3}{*}{ Centre } & \multicolumn{3}{|c|}{ Zymodemes (number of strains) } & \multirow[b]{3}{*}{ Total } \\
\hline & \multicolumn{2}{|c|}{ Human leishmaniasis } & \multirow{2}{*}{$\begin{array}{c}\text { Canine leishmaniasis } \\
\mathrm{VL}^{*}\end{array}$} & \\
\hline & $\mathbf{V L}^{*}$ & $\mathbf{C L} \mathbf{L}^{* *}$ & & \\
\hline Monastir & $\begin{array}{l}\text { L. infantum MON-1 (14) } \\
\text { L. infantum MON-24 (02) }\end{array}$ & L. major MON-25 (07) & L. infantum MON-1 (24) & 47 \\
\hline Mahdia & & L. major MON-25 (12) & - & 12 \\
\hline Kairouan & $\begin{array}{l}\text { L. infantum MON-1 (12) } \\
\text { L. infantum MON-24 (08) } \\
\text { L. infantum MON-80 (01) }\end{array}$ & $\begin{array}{l}\text { L. major MON-25 (38) } \\
\text { L. infantum MON-24 (01) } \\
\text { L. killicki MON-8 (01) }\end{array}$ & L. infantum MON-1 (03) & 64 \\
\hline Sousse & - & L. major MON-25 (06) & - & 06 \\
\hline Sidi Bouzid & - & $\begin{array}{l}\text { L. major MON-25 (28) } \\
\text { L. killicki MON-8 (01) }\end{array}$ & - & 29 \\
\hline South & & & - & \\
\hline Sfax & - & $\begin{array}{l}\text { L. major MON-25 (63) } \\
\text { L. infantum MON-24 (02) }\end{array}$ & L. infantum MON-1 (18) & 83 \\
\hline Gafsa & - & L. major MON-25 (07) & - & 07 \\
\hline Tozeur & - & L. major MON-25 (03) & - & 03 \\
\hline Tataouine & - & $\begin{array}{l}\text { L. major MON-25 (02) } \\
\text { L. killicki MON-8 (07) }\end{array}$ & - & 09 \\
\hline Kébilli & - & L. major MON-25 (03) & - & 03 \\
\hline Kasserine & - & L. major MON-25 (03) & - & 03 \\
\hline Total & 37 & 184 & 45 & 266 \\
\hline
\end{tabular}

*VL: visceral leishmaniasis; ** CL: cutaneous leishmaniasis.

Table I. - Result of the identification of strains according to host, clinical form and focus. 
rence des Leishmania Montpellier, France: MHOM/FR/ 78/LEM75, L. infantum MON-1, MHOM/DZ/82/LIPA59, L. infantum MON-24, MHOM/MA/81/LEM265, L. major MON-25 and MHOM/TN/LEM163, L. killicki MON-8.

\section{METHODS}

The strains were isolated by culture on Nicolle-NovyMacNeal (NNN) medium and characterized by the iosenzymatic technique using starch gel electrophoresis according to Rioux et al., 1990. The following 15 enzyme systems were studied: malate dehydrogenase (MDH, EC 1.1.1.37), malic enzyme (ME, EC 1.1.1.40), isocitrate dehydrogenase (ICD, EC 1.1.1.42), phosphogluconate dehydrogenase (PGD, EC 1.1.1.44), glucose-6-phosphate dehydrogenase (G6PD, EC 1.1.1.49), glutamate dehydrogenase (GLUD, EC 1.4.1.3), diaphorase NADH (DIA, EC 1.6.2.2), nucleoside purine phosphorylases 1 and 2 (NP1, EC 2.4.2.1. and NP2, EC 2.4.2.*), glutamate oxaloacetate transaminases 1 and 2 (GOT1 and GOT2, EC 2.6.1.1), phosphoglucomutase (PGM, EC 5.4.2.2), fumarate hydratase (FH, EC 4.2.1.2), mannose phosphate isomerase (MPI, EC 5.3.1.8) and glucose phosphate isomerase (GPI, EC 5.3.1.9).

\section{RESULTS}

D uring eight years, 266 strains were isolated from provinces of the Centre and the South of the country and were identified by isoenzymatic method. Three complexes and five zymodemes were present (Table I).

For the 184 strains isolated from human CL, three complexes were identified: as $L$. major zymodeme MON25 ( $\mathrm{n}=172$ strains, $93 \%$ ), L. killicki MON-8 ( $\mathrm{n}=$ 09 strains, $5 \%$ ) and L. infantum MON-24 ( $=3$ strains, $2 \%$ ). All isolates from human and canine visceral leishmaniasis belonged to L. infantum complex.

\section{LEISHMANIA INFANTUM COMPLEX}

Human visceral leishmaniasis

Isoenzymatic identification of 37 isolates from bone marrow or peripheral blood of patients revealed three zymodemes of L. infantum: zymodeme MON-1 is predominant ( $\mathrm{n}=26$ strains, $70 \%)$. The second zymodeme is the dermotropic one MON-24 ( $\mathrm{n}=10$ strains, $27 \%)$. However, L. infantum MON-80 is sporadic with a single strain (3\%).

All strains were isolated from patients originating from two central provinces: Monastir and Kairouan. $i$ ) In Monastir province, 16 human strains were characterized. Among them, 12 were from child between one and three years old. The four other were from three adult of 36, 39 and 76 years old. All strains belonged to the same complex L. infantum: 14 were L. infantum MON1 and two were L. infantum MON-24. These two strains

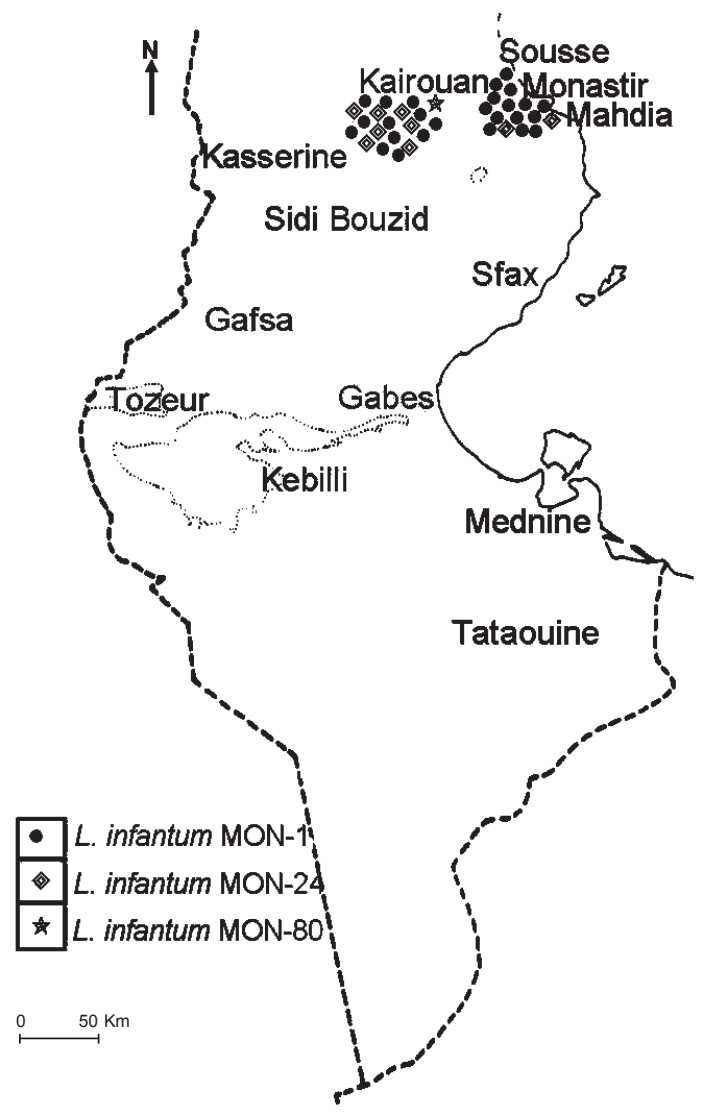

Fig. 1. - Geographical distribution of Leishmania strains isolated from human visceral leishmaniasis cases, according to their zymodemes.

were isolated from two children coming from Ouardanine and Moknine localities. $i$ i) In Kairouan province, 21 strains were obtained from children with VL. Their age ranged between one and three years old. 12 strains were identified as L. infantum MON-1 (57 \%), eight strains were identified as L. infantum MON-24 (38 \%) and one strain as L. infantum MON-80 (5 \%) (Fig. 1).

Human cutaneous leishmaniasis

Three isolates belonging to L. infantum complex were obtained from patients with CL from the Centre and the South part of Tunisia (Fig. 2): out of them, one was originating from Kairouan which is a neighboring province to Seliana, the classical focus of SCL. The two others strains were surprisingly isolated from two patients originated from M'Satria district of Sfax (Southern Tunisia). This complex was never been described in this geographical arid region. All these strains were identified as $L$. infantum zymodeme MON-24. This zymodeme was classically described to be the causative agent of sporadic cutaneous and visceral leishmaniasis in Northern Tunisia.

Canine visceral leishmaniasis

45 strains of Leishmania were isolated from canine VL. All of them come from canine VL and no one from 


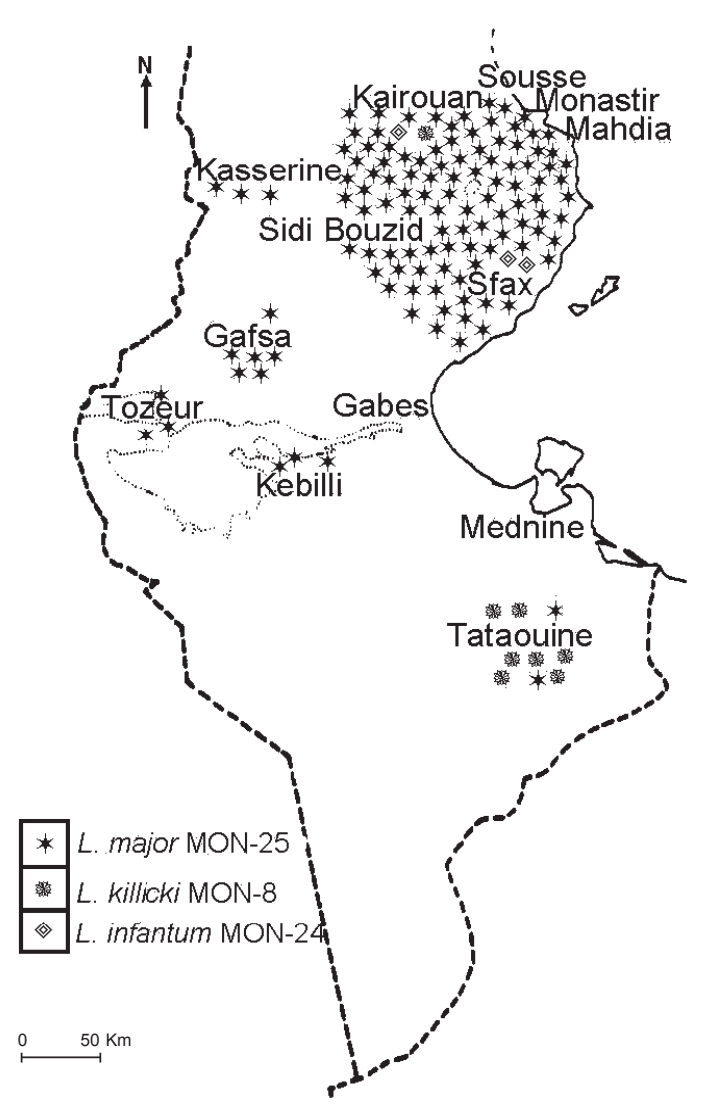

Fig. 2. - Geographical distribution of Leishmania strains isolated from human cutaneous leishmaniasis cases, according to their zymodemes.

canine CL. Among of these isolates, eighteen were obtained from field epidemiological investigations in Sfax province in South East Tunisia ( $n=18$ strains). The 27 other strains come from Monastir and Kairouan delegations in the Centre and were collected from veterinary diagnostic services. All these isolates belonged to L. infantum with the single zymodeme MON-1 (Fig. 3).

\section{LEISHMANIA MAJOR COMPLEX}

Human cutaneous leishmaniasis

184 strains from cutaneous leishmaniasis were studied; of which, 94 strains were collected from central Tunisia and 90 from South part of the country (Fig. 2). Out of these strains, 172 strains (93\%) belonged to L. major zymodeme MON-25. As expected, these strains originated from the main endemic foci of ZCL: Kairouan province (38 strains, $22 \%$ ), Sfax province (63 strains, $37 \%$ ), Sidi Bouzid province (28 strains, $16 \%$ ), Mahdia (12 strains, $7 \%$ ), Gafsa (seven strains, $4 \%$ ) and Monastir (seven strains, $4 \%$ ).

Few other isolates were collected from other regions such as Sousse (six isolates), Tataouine (two isolates), Tozeur (three isolates), Kebilli (three isolates) and Kasserine (three isolates) ( $\mathrm{n}=17$ strains, $10 \%$ together).

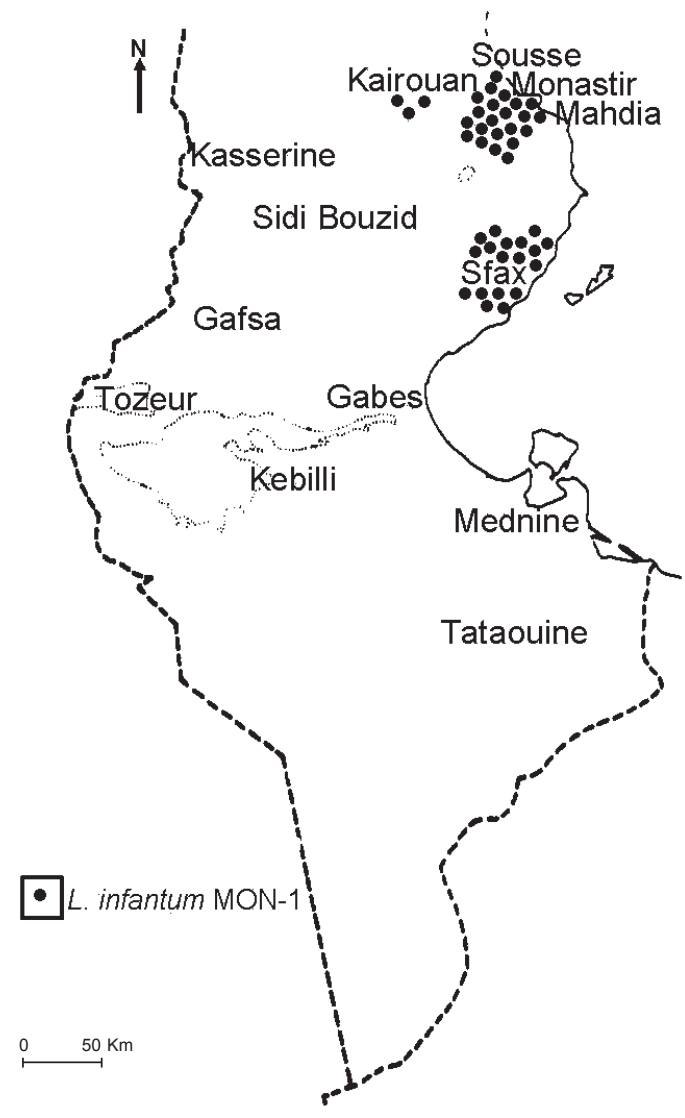

Fig. 3. - Geographical distribution of Leishmania infantum MON-1 strains isolated from canine visceral leishmaniasis.

\section{LEISHMANIA KILLICKI COMPLEX}

Out of the 184 strains isolated from human CL, nine strains were characterized as L. killicki MON-8. This zymodeme was already described to be the causative agent of chronic CL which has a limited geographical area in the micro focus of Tataouine Southeast Tunisia. Two strains of this zymodeme were obtained from new foci outside Tataouine: one strain from Kairouan and one from Meknassy (delegation of Sidi bouzid). The seven others strains were isolated from patients originating and living in Tataouine province.

\section{DISCUSSION}

2 66 strains is the current biggest number of strains identified in Tunisia. Indeed, many studies were carried on the prevalence of cutaneous and visceral leishmaniasis in Tunisia but the characterization of the parasite was hardly ever made (Ben Salah et al., 2000; Kharfi et al., 2004). Previously, 65 was the largest number of identified VL strains. The majority of these studied strains originated from eight provinces of northern Tunisia (Belhadj et al., 2002). For the cuta- 
neous leishmaniasis, the most exclusive study has analysed 71 strains of Leishmania. The majority of them were isolated from the North part of the country (Kallel et al., 2005). So leishmaniasis disease in Centre and South of Tunisia was rarely investigated and no recent data on the characterization of the parasite were published. This prospective study updates the result of identification of Leishmania in the Centre and the South of Tunisia during the last eight years.

The identification of the 266 strains (from human and canine hosts and from different origins) allowed to individualize three Leishmania complexes responsible of CL and a single one for VL.

\section{LEISHMANIA INFANTUM FOCI}

\section{Human visceral leishmaniasis}

Tunisia has been considered as an endemic country for VL disease since the description of the first case in 1904 (Laveran \& Cathoire, 1904). Since then, this form has not stopped to increase in incidence: 11 cases were registered in pediatrics department in 1970 against 16 cases in 1978 (Ben Rachid et al., 1983).

Then, an outbreak occurred in 1980 with 21 cases in the "Hôpital d'Enfant" of North Tunisia and in 1988 with 16 cases in the same hospital (Khaldi et al., 1991). The last census was reported in 1993 with 150 cases per year (Bouratbine et al., 1998).

Initially, VL was distributed in the North of Tunisia. It covered all humid and subhumid biolimatic zones. After a few years, transmission area of this leishmaniasis form has outstandingly extended toward the Centre and the South of Tunisia but no identification of the causative agent species was done (Ayadi et al., 1991; Ben Salah et al.2000).

37 strains of VL were isolated from patients originating from the Centre of Tunisia. About $90 \%$ of them came from children between one and three years old. The infantile feature of the disease is the same of northern Tunisia which indicate the continuity of this focus from the North to the Centre of the country.

Three enzymatic variants of $L$. infantum complex were isolated from immunologically competent patients: L. infantum MON-24, L. infantum MON-80 and L. infantum MON-1. The latter was predominant (70 \% of VL strains) as well as in other Mediterranean countries such as Algeria and South France (Harrat et al., 1996; Pratlong et al., 2004). The 26 strains, belonged to L. infantum MON-1, are distributed in two central provinces: 12 strains were from Kairouan and the 14 other were from Monastir province. Previously, this governorate was never been concerned by this leishmaniasis form and no case was reported. Since few years, sporadic cases were declared in EPS Fattouma Bourguiba Monastir and the emergence of this leishmaniasis form seems to be the consequence of the establishment of a new stable Leishmania infantum transmission cycle. The maintenance of this cycle could be helped by the existence of intensive agriculture in the rural areas of this province.

In spite being the main agent of VL in immunocompetent children, zymodeme MON-1 was also responsible for VL in immunosupressed patients with HIV infection in France and Spain (Pratlong et al., 1995). Here, we report four strains of $L$. infantum MON-1 isolated from three HIV negative adults of 36, 39 and 65 years old. Among these three patients, one was suffering from a chronic kidney disease.

Zymodeme MON-24 was previously considered to be a dermotropic zymodeme causative of sporadic CL in northern Tunisia (Aoun et al., 2000). In 1991, this zymodeme was isolated for the first time from a child with VL in the North (Gramiccia et al. 1991) than confirmed by Belhadj et al., in 2000 .

In this report, we identify two new cases of L. infantum MON-24 in the Monastir province and eight other cases in Kairouan province.

Finally, the only case of $L$. infantum MON-80 was also isolated for the first time in the Kairouan Province. Until now, only four cases of $L$. infantum MON-80 were described in Tunisia (Aoun et al., 2001; Belhadj et al., 2002). All cases were reported in the North part of the country including Zaghouan province which has frontier with Kairouan province. This could confirm the geographical spread of this zymodeme to the neighboring area. This spread could be enhanced by the migration of the reservoir which is still unknown.

In total, 21 strains of VL, belonged to the three zymodemes of L. infantum complex, were isolated from patients originating from Kairouan province. This makes Kairouan province an interesting focus which assembles the three zymodeme of L. infantum behind L. major complex. The establishment of the transmission cycle of the two complexes would be in part the consequence of the building of the new dam last few years. This new source of water and organic materials would increase the phlebotomus population density the vector of Leishmania.

\section{Human cutaneous leishmaniasis}

In Tunisia, CL due to L. infantum is qualified as a sporadic disease located in the northern part of the country. Two zymodemes were reported in this form of leishmaniasis: zymodeme MON-24 was described as a predominant agent of sporadic CL in Seliana province in the North (Bel Hadj et al., 2002a). It is also encountered in neighboring countries such as Algeria and Morocco (Gramiccia et al., 1991; Harrat et al., 1996). However, the zymodeme MON-1 was isolated for the first time in 1999 in the North (Aoun et al., 2000).

Among the studied isolates, three strains were identified as L. infantum MON-24: one was isolated from a 
patient originating from Kairouan. This province has frontier with the classical focus of this complex, Seliana. However, the two others strains were unexpectedly isolated from M'Satria district in Sfax province. This region belongs to the arid bioclimatic level where vector species of this complex could not exist. A thoroughly investigation of the history travel of the two patients shows that they had never left this region. So by reporting these two cases, we provide evidence for the presence of this zymodeme in a new focus and the geographical emergence of the MON-24 zymodeme in the south of Tunisia. This preliminary result must be continued by making other entomological and ecological studies in this new focus.

Canine visceral leishmaniasis

Conversely to the anthroponotic VL in India (Ross 1903), Mediterranean countries including Tunisia have a zoonotic type. In fact, in Tunisia, domestic dog has been incriminated in VL since the report of the first case of infected dog in 1908 (Nicolle \& Comte, 1908). 45 strains of canine VL were studied. Out of them, 18 strains were obtained during epidemiological investigations carried out in the region of Sfax and 27 others were collected from veterinary service in the context of diagnosis.

Among canine VL strains, 18 were coming from Sfax region in the southern part of the country where no human VL case was isolated. The canine strains were isolated from infected dog originated from localities neighboring to endemic central foci of VL. This finding showed that VL exists in this region but the absence of data regarding human VL may be the consequence of the insufficient relationships with local practitioners in Sfax region.

All these strains were identified as L. infantum zymodeme MON-1. This confirms the role of domestic dog as the exclusive reservoir host of human VL due to the zymodeme MON-1 of L. infantum complex. This result was already reported in others Mediterranean countries as Spain (Martin-Sanchez et al., 2004). However, other zymodeme of L. infantum complex were also isolated from dogs such as MON-77 in the Catalan focus in Spain (Gallego et al., 2001) and MON-108 in Provence France (Pratlong et al., 2004).

\section{LEISHMANIA MAJOR FOCI}

Leishmania major zymodeme MON-25 was described to be the causative agent of ZCL in Tunisia and in other Maghreb's countries as Morocco and Algeria (Harrat et al., 1996; Rioux et al., 1990).

This form of leishmaniasis is widely distributed in the central and southern part of the country covering the arid and semi arid bioclimatic zones. The first case was described in 1884; since then ZCL did not stop pro- gressing: between 2000 and 2002, four new cases were reported in the North part of Tunisia which is a non endemic focus of this leishmaniasis form (Kallel et al., 2005).

Life cycle of the causative agent L. major was clearly elucidated with Phlebotomus (P.) papatasi as the vector (Rioux et al., 1986a) and Psammomys obesus and Meriones shawi as reservoir rodents (Ben Hamou et al., 2006). As expected, in our study all L. major strains were distributed in the Centre and the South of Tunisia. The most number of strains were located in Kairouan, Sidi Bouzid and Sfax regions. All these regions belonged to the arid and per arid bioclimatic levels where rodents and $P$. papatasi are wildly spread and a stable transmission cycle is already present.

\section{LEISHMANIA KILLICKI FOCI}

Leishmania killicki was described for the first time in 1980 during an investigation in the micro focus of Tataouine south eastern Tunisia (Rioux et al., 1986b). Since this date and for many years, no strains belonging to this zymodeme has been isolated out side this region.

In 2004, three strains were isolated in three new foci, Seliana, Sidi Bouzid and Gafsa showing the beginning of spread of this zymodeme to the south western and the northern part of Tunisia (Haouas et al., 2005). In the same year, three other strains were isolated in Oueslatia district of Kairouan province in central Tunisia and were characterized as L. killicki proving this extension of the anthroponotic CL (Bouratbine et al., 2005).

During our study, we identify two strains in new foci outside Tataouine province: Sidi Bouzid and Kairouan. These areas belong to different vegetation level. This finding proves one more time the extension of this focus which must be investigated by ecological study of this new area.

\section{CONCLUSION}

This report provides additional data for the studying of cutaneous and visceral leishmaniasis in the Centre and the South of Tunisia. The inclusion of such a number of strains in this study had allowed concluding to the conservation of geographical distribution of $L$. major foci, the extension of the L. infantum foci and the emergence of a new focus of L. infantum MON-24 in Sfax province.

Surely, this study brings more data for the knowledge of the spatial and temporal geographical distribution evolution of the existing Leishmania foci but it is not enough to elucidate the transmission cycle of each zymodeme. More investigations concerning the phle- 
botomine species cartography and the study of the sand flies host preference will be very useful to response to the remains questions.

\section{ACKNOWLEDGEMENTS}

T his work was supported by the finances from the Tunisian Ministry of Scientific Research, Technology and Competences Development.

\section{REFERENCES}

Aoun K., Bouratbine A., Harrat, Z., Bellaid M. \& BelHadj Ali S. Profil particulier des zymodèmes de L. infantum causant la leishmaniose viscérale en Tunisie. Bulletin de la Société de Pathologie Exotique, 2001, 94 (5), 375-377.

Aoun K., Bouratbine A., Harrat Z., Guizani I., Mokni, M., BelHadj Ali S., Ben Osman A., Belkaid M., Dellagi, K. \& BEN Ismail R. Données épidémiologiques et parasitologiques concernant la leishmaniose cutanée sporadique du nord tunisien. Bulletin de la Société de Pathologie Exotique, 2000, 93, 101-103.

Ayadi A., Ben Ismail R. \& Ben Rachid M.S. Extension de l'aire de transmission du kala-azar à Leishmania infantum (Nicolle, 1908) vers le centre et le sud de la Tunisie. Archives de l'Institut Pasteur de Tunis, 1991, 68, 269-273.

Bel Hadj S., Pratlong F., Hammami M., Kallel K., Dedet J.P. \& ChaKer E. Human cutaneous leishmaniasis due to Leishmania infantum in the Sidi Bourouis focus (Northern Tunisia): epidemiological study and and isoenzymatic characterization of the parasites. Acta Tropica, 2002a, 85, 8386.

Bel Hadj S., Pratlong F., Mahjoub H., Toumi N. H., Azaiez R., DEDET J.P. \& CHAKER E. Leishmaniose viscérale infantile à Leishmania infantum MON-24: une réalité en Tunisie. Bulletin de la Société de Pathologie Exotique, 2000, 93, 12 13.

Bel Hadj S., Pratlong F., Toumi N.H., Kallel K., Mahjoub H., Babba H., Azaiez R., Dedet J.P. \& Chaker E. Visceral leishmaniasis in Tunisia: result of the isoenzymatic characterization of 65 Leishmania infantum strains. Transactions of the Royal Society of Tropical Medicine and Hygiene, 2002b, 96 (6), 627-630.

Ben Hamou M., Ben Abderrazak S., Frigui S., Chatti N. \& Ben Ismail R. Evidence for the existence of two distinct species: Psammomys obesus and Psammomys vexillaris within the sand rats (Rodentia, Gerbillinae), reservoirs of cutaneous leishmaniasis in Tunisia. Infection, Genetics and Evolution, 2006, 6 (4), 301-308.

Ben Rachid M.S., Hamza B., Tabbane C., Gharbi R., Jedidi H. \& BEN SAID M. État actuel des leishmanioses en Tunisie. Annales de la Société Belge de Médecine Tropicale, 1983, 63, 29-40.

Ben Salah A., Ben ismail R., Amri F., Chlif S., Ben Rzig F., Kharrat H., Hadhri H., Hassouna M. \& Dellagi K. Investigation of the spread of human visceral leishmaniasis in central Tunisia. Transactions of the Royal Society of Tropical Medicine and Hygiene, 2000, 94, 382-386.

Bouratbine A., Aoun K., Chahed M.K. \& Ben Ismail R. Données épidémiologiques sur la leishmaniose viscérale infantileen Tunisie en 1993. Médecine et Maladies Infectieuses, 1998, 28, 446-447.

Deperet C. \& Bobinet E. Du bouton de Gafsa au champ de Sathonay. Archives Médicales et Pharmaceutiques Militaires, 1884, 3, 296-302.

Gallego M., Pratlong F., Fisa R., Riera C., Rioux J.A., Dedet J.P. \& PORTUS M. The life cycle of Leishmania infantum MON-77 in the Priorat (South of Catalonia, Spain) involves humans, dogs and sandflies. Transactions of the Royal Society of Tropical Medicine and Hygiene, 2001, 95, 269271.

Gramiccia M., Ben-Ismail R., Gradoni L., Ben-Rachid M.S. \& BEN-SAID M. A Leishmania infantum enzymatic variant, causative agent of cutaneous leishmaniasis in North Tunisia. Transactions of the Royal Society of Tropical Medicine and Hygiene, 1991, 85, 370-371.

Haouas N., Chargut N., Chaker E., Ben Said M., Babba H., Belhadj S., Kallel K. Pratlong F., Dedet J.P., Mezhoud H. \& AzAIEZ R. Anthroponotic cutaneous leishmaniasis in Tunisia: presence of Leishmania killicki outside its original focus of Tataouine. Transactions of the Royal Society of Tropical Medicine and Hygiene, 2005, 99, 499-501.

Harrat Z., Pratlong F., Belazzoug S., Derreure J., Deniau R., Rioux J., BelKaid M. \& Dedet J.P. Leishmania infantum and L. major in Algeria. Transactions of the Royal Society of Tropical Medicine and Hygiene, 1996, 90, 625-629.

Kallel K., Pratlong F., Bel Hadj S., Cherif F., Hammami M., Dedet J.P. \& Chaker E. Cutaneous leishmaniasis in Tunisia: result of isoenzymatic characterization of 71 strains. Annals of Tropical Medicine and Parasitology, 2005, 99 (1), 1119.

Khaldi F., Achouri E, Gharbi A., Debbabi A. \& Ben Naceur B. Leishmaniose viscérale de l'enfant. Étude des cas hospitalisés de 1974 à 1988 à l'hôpital d'enfant de Tunis. Médecine tropicale, 1991, 51, 143-147.

Kharfi M., Benmously R., El Fekih N., Daoud M., Fitouri Z., Mokhtar I., Ben Becher S. \& Kamoun M.R. Childhood leishmaniasis: report of 106 cases. Dermatology Online Journal, 2004, 10 (2), 6.

Lanotte G., Rioux J.A., Maazoun R., Pasteur N., Pratlong F. \& LEPART J. Application de la méthode numérique à la taxonomie du genre Leishmania Ross, 1903 : à propos de 146 souches originaires de l'Ancien Monde. Utilisation des allozymes. Corollaire épidémiologique phylétique. Annales de Parasitologie Humaine et Comparée, 1981, 56, 575-592.

Laveran A. \& Cathoire M. Présentation du parasite Piroplasma donovani. Bulletin de l'Académie de Médecine, 1904, 51, 247-248.

Martin-Sanchez J., Gramiccia M., Di Muccio T., Ludovisi A. \& Morillas-MarquEz F. Isoenzymatic polymorphism of Leishmania infantum in southern Spain. Transactions of the Royal Society of Tropical Medicine and Hygiene, 2004, 98, 228-232.

Nicolle C. \& COMTe C. Origine canine du kala-azar. Bulletin de la Société de Pathologie Exotique, 1908, 1, 299-301. 
Pratlong F., Dedet J.P., Marty P., Pertus M., Deniau M., Dereure J., Abranches P., Reynes J., Martini A., Lefebvre M. \& Rioux J.A. Leishmania-human imminodeficiency in the mediterranean bassin : iso enzymatic characterization of 100 isolates of the Leishmania infantum complex. Journal of Infectious Diseases, 1995, 172, 323-326.

Pratlong F., Rioux J.A., Marty P., Faraut-Gambarelu F., Dereure J., LANOTTE G. \& Dedet J.P. Isoenzymatic analysis of 712 strains of Leishmania infantum in the south of France and relationship of enzymatic polymorphism to clinical and epidemiological features. Journal of Clinical Microbiology, 2004, 42, 4077-4082.

Rioux J.A., Guilvard E., Dereure J., Lanotte G., Deniau M., Pratlong F., Serre E. \& Belmonte A. Infestation naturelle de Phlebotomus papatasi (Scopoli, 1786) par Leishmania major MON-25. À propos de 28 souches isolées dans un foyer du Sud-Maroccain. In: Leishmania. Taxonomie et phylogenèse. Applications éco-épidémiologiques. Rioux J.A. (éd.). IMEEE, Montpellier, 1986a, 471-480.

Rioux J.A., LANotte G. \& Pratlong F. Leishmania killicki n. sp (kinetoplastida: trypanosomatidae) In: Leishmania. Taxonomie et phylogenèse. Applications éco-épidémiologiques. Rioux J.A. (éd.). IMEEE, Montpellier, 1986b, 139-142.

Rioux J.A., Lanotte G., Serre E., Pratlong F., Bastien P. \& PÉrIÈres J. Taxonomy of Leishmania. Use of isoenzymes suggestions for new classification. Annales de Parasitologie Humaine et Comparée, 1990, 65, 111-125.

Ross R. Note on the bodies recently described by Leishman and Donovan. British Medical Journal, 1903, 14, 12611262.

Zahaf A., Jarray A., SARHani S., LANOtTe G. \& Périères J. Leishmania major Yakimoff et Shokhor 1914 dans les gouvernorats de Sidi Bouzid et Gafsa (Tunisie). Note préliminaire. In: Leishmania. Taxonomie et phylogenèse. Applications éco-épidémiologiques. Rioux J.A. (éd.). IMEEE, Montpellier, 1986, 41-55.

Reçu le 13 décembre 2006 Accepté le 7 mars 2007 